\title{
¡qué aridez de imaginación pedagógica! pensar la escuela más allá de lo
}

\section{(im)posible}

\author{
colectivo filosofar con chicxs ${ }^{1}$ \\ universidad de buenos aires - argentina
}

resumen

La pregunta que motoriza el presente trabajo es la siguiente: ¿Por qué, a pesar de todos los cambios político-curriculares y didácticos de los últimos tiempos, seguimos sintiendo que la escuela está encorsetada en la reproducción de lo mismo? ¿Acaso nuestra época no está signada por una falta de imaginación pedagógica? Nos preguntamos por la manera en que nuestra imaginación -como facultad de producir representaciones más allá de lo dado- está configurada en la actualidad. Y observamos que a pesar de que se la presenta como una capacidad ilimitada, parece tener demarcaciones muy claras. Creemos que en la actualidad, todavía seguimos muy atados al imaginario pedagógico moderno. Podemos, no obstante, identificar ciertas prácticas que han permitido salir de ese plano de representaciones y romper con ese imaginario establecido, con el campo de lo ya dado, constituyendo gestos de "imaginación pedagógica radical". Estos gestos inciden en el modo en que se distribuyen las visibilidades y las invisibilidades de lo que logramos o no concebir como posible en el campo educativo. Los interrogantes que nos motivan, lejos de constituir diagnósticos cerrados o concluyentes, pretenden problematizar el campo educativo a través de la desnaturalización de nuestra subjetividad docente y de la dilucidación del modo en que nuestras miradas, nuestras prácticas y nuestros deseos colectivos son configurados en gran medida por dispositivos socio-históricos y por representaciones que se materializan en relaciones y valoraciones educativas verticalistas y adultocéntricas. El aporte principal del presente trabajo consiste en la propuesta de ver en los conceptos de caos-acontecimiento y de prefiguración pedagógica-desarrollados en anteriores trabajos- la posibilidad de movilizar el campo de la imaginación pedagógica de nuestra época hacia otras prácticas educativas posibles, que irrumpan en los dispositivos de la escuela moderna, anticipando en el presente la escuela que deseamos y dando espacio a que sean los propios niños y jóvenes quienes aporten a la configuración de nuevos escenarios educativos posibles.

palabras claves: escuela; imaginación; prefiguración; pedagogía; infancia

que aridez de imaginação pedagógica! pensar a escola além do (im)possível

resumo

A questão que impulsiona o presente trabalho é: Porque, apesar de todas as mudanças político-curriculares e pedagógicas dos últimos tempos, continuamos sentindo que a escola está espartilhada na reprodução do mesmo? Será que a nossa época está marcada por uma falta de imaginação pedagógica? Nos perguntamos pela maneira em que a nossa imaginação -como faculdade de producir representações além do que já foi definido - está configurada na atualidade. E observamos que apesar de ser apresentada como uma capacidade ilimitada, parece ter demarcações muito claras. Acreditamos que na atualidade, continuamos a estar muito ligados aoimaginário pedagógico moderno.

\footnotetext{
${ }^{1}$ E-mail: filosofarconchicos@gmail.com
} 
Podemos, no entanto, identificar certas práticas que tem permitido abandonar ese plano das representações e romper com ese imaginário estabelecido, com o campo do que já foi definido, constituindo-se, assim, em gestos de "imaginação pedagógica radical." Esses gestos influenciam o modo no qual são distribuidas as visibilidades e invisibilidades do que conseguimos ou não conceber como possível no campo educacional. As questões que nos motivam, longe de se constituirem em diagnósticos fechados ou conclusivos, pretendem problematizar o campo educacional através de desnaturalização da nossa subjetividade docente e da elucidação do modo em que nossos olhares, ,nossas práticas e nossos desejos coletivos são configurados em grande parte por dispositivos sóciohistóricos e por representações que se materializam em relações e avaliações educacionais verticalistas e adultocêntricas. A principal contribuição do presente trabalho consiste na proposta de enxergar nos conceitos de caos-acontecimento e de prefiguração pedagógica desenvolvidos em trabalhos prévios - a possibilidade de mobilizar o campo da imaginação pedagógica da nossa epoca para outras práticas educacionais possíveis, irrompeendo nos dispositivos da escola moderna, antecipando no presente a escola que desejamos e dando espaço para que sejam as próprias crianças e os jovens quem contribuam na configuração de novos cenários educacionais possíveis.

palavras-chave: escola ; imaginação ; prenúncio ; pedagogia ; infancia

\section{what smash of pedagogical imagination! thinking school beyond (im) possible}

abstract

This paper is motorized by the following question: Why, although there have been many changes on curricular policies and didactic designs during the last years, do we continue feeling that the school is still trapped in the reproduction of the same? May our times be signed by the lack of pedagogical imagination? We wonder about the ways in which our imagination-as the faculty to produce representations beyond what 's given-is configured in the present. And we observe that although it is presented as an unlimited faculty, it seems to have clear demarcations. We believe that at present time, we are still tied up to the modern pedagogical imaginary. However, we can identify a few practices that allow us to move from those representations, questioning the established imaginary which give place to what we call gestures of "radical pedagogical imagination". These gestures have an impact on the way we distribute the visibilities and invisibilities of what we are able or not to consider possible in the educational field. The questions that have motivated us, far from being closed or conclusive diagnostics, pretend to inquire the educational field, through the questioning of our teacher's subjectivity and the critical analysis of the way in which our perspectives, our practices and our collective desires are configured by sociohistoric devices and representations that are materialized in vertical and adult-centric educational values and relationships. The main contribution of this paper is the proposal of seeing in the concepts of chaos-events and pedagogical-prefiguration-developed during previous papers- the possibility of moving, the field of pedagogical imagination, to other kind of possible educative practices, that can break the devices of modern school, anticipating at the present the school we want, giving place and letting the children and young people to be the ones that contribute to the creation of a new possible educative scenario.

keywords: school, imagination, prefiguration, pedagogy, childhood. 
¡qué aridez de imaginación pedagógica! pensar la escuela más allá de lo (im)posible

\begin{abstract}
"Ahora bien, hoy, entre nosotros, iqué aridez de imaginación política!".
No podemos sino sorprendernos ante esta pobreza. En ese sentido, estamos en las antípodas de los hombres de los siglos XVIII y XIX."
\end{abstract}

(FOUCAULT, 2012, p. 91)

En una entrevista en 1978 (FOUCAULT, 2012, p. 91), Foucault describe su época con la expresión recién citada, en referencia a la falta de herramientas teóricas superadoras del marxismo ortodoxo que existía en su momento. Hoy en día, aún cuando múltiples movimientos y organizaciones sociales intentan resistir el modo hegemónico de vida capitalista, nos cuesta imaginar la existencia de sistemas y modos de vida alternativos.

Si pensamos desde esta perspectiva el ámbito educativo, nos preguntamos: ¿Por qué, a pesar de todos los cambios político-curriculares y didácticos de los últimos tiempos, seguimos sintiendo que la escuela está encorsetada en la reproducción de lo mismo? ${ }^{2}$ ¿Es posible realizar cambios que tengan como horizonte la transformación de la escuela tradicional? ¿Cómo pensarlos?

\footnotetext{
${ }^{2}$ Con esta pregunta lo que intentamos problematizar es una percepción que compartimos en lo que respecta a algunas transformaciones que se han realizado en la escuela primaria pública de nuestro país, Argentina, durante las últimas décadas. Las fuentes de esta percepción y el cuestionamiento que nos realizamos, son tanto las lecturas teóricas realizadas de diversos textos que repiensan la educación moderna y la actual (ver Bibliografia), como también la experiencia del propio tránsito por estas instituciones educativas que hemos tenido como estudiantes en la década de los ' $80 \mathrm{y}$ luego como docentes hacia finales de la primera década del 2000.Para nosotrxs es innegable que en este contexto educativo han habido modificaciones e innovaciones, como por ejemplo: la introducción de la tecnología y la explosión de sus posibilidades al interior y al exterior del aula, la valoración y el respeto por la palabra de lxs chicxs, la importancia de los saberes previos a la hora de introducir temas, el cuestionamiento del castigo como una forma de aprendizaje, la pérdida de la importancia del aprendizaje memorístico, entre otros. Pero también consideramos que más allá de estos cambios se puede constatar al interior de las instituciones determinadas estructuras y modos de organización que no han sido modificados. Estas constantes permiten la vigencia de la idea en discursos, sentidos comunes e investigaciones de lo que se llama y se engloba con la caracterización de "crisis de las instituciones educativas modernas" y también de las investigaciones que procuran transformarlas. Ejemplos de estas constantes que todavía se puede experimentar al transitar estas instituciones pueden ser: la distribución del tiempo (un tiempo lineal, con metas prefijadas de antemano, división tajante entre tiempo de ocio y tiempo de estudio, etc.) y del espacio (tanto con respecto al mobiliario y la dificultad de cambiar de lugar bancos o escritorios, así como al lugar asignado tanto al docente como al estudiante), la fragmentación de las disciplinas, la división de lxs niñxs por edades, la jerarquía en la toma de decisiones que deja a un lado los deseos y voluntades de lxs chicxs en el modo y en el contenido de su educación, entre
} 
Podría suponerse que el delineado de los modos de educar, de enseñar y de aprender dependen de la puesta en juego de facultades tales como la razón. ¿Por qué entonces acudir a la imaginación en lugar de a la razón? Consideramos que todo ordenamiento racional, lleva implícitas ciertas formas de mirar y de concebir el mundo. Lo racional -instrumento por antonomasia de la modernidad- que ordena y jerarquiza, opera sobre representaciones sociales que ya están dadas y se configuran más allá de la razón. Dichas representaciones se institucionalizan formando un determinado imaginario social, por lo cual, se puede concebir a la imaginación como la facultad capaz construirlo y de generar dichas representaciones. Creemos que la apelación a la imaginación tiene relevancia y potencia, porque sus producciones, lejos de constituir "reflejos" o "copias" de "lo real", son creaciones que pueden siempre reconfigurarse ${ }^{3}$.

Si pensamos a la imaginación como nuestra facultad de producir representaciones más allá de lo dado, la misma se presenta como una facultad ilimitada. Entonces, ¿acaso nuestra época no está signada por una falta de imaginación pedagógica? ¿No deberíamos ser más imaginativxs ${ }^{4}$, para que sea posible producir

otras. Estas estructuras se generaron con la concepción de la educación moderna y a eso nos referimos con la frase "reproducción de lo mismo", ya que intentamos pensar la posibilidad de una educación que sea radicalmente distinta de la anterior. Más adelante se retoma específicamente esta cuestión.

${ }^{3}$ Esta decisión teórica de privilegiar la facultad de la imaginación por sobre la facultad de la razón, se basa fundamentalmente en la delimitación que realiza Castoriadis (CASTORIADIS, 2007) de dichas facultades y sus funciones. El autor propone, y acordamos con él, que la imaginación es la productora de representaciones, formando un determinado imaginario social, y la razón es la encargada de ordenarlas, jerarquizarlas, evaluarlas. La imaginación no se opone a lo real sino a lo racional (FRESSARD, 2006), que ordena y determina, produce lo determinado, es decir, establece límites y distinciones, mientras que la potencia creadora tiene que ver con la imaginación, que produce lo nuevo, lo indeterminado. El imaginario social es un marco socio-histórico de representaciones que modelan la subjetividad, que se instituyen racionalmente, pero que a su vez, pueden ser transformadas porque siempre algo de la imaginación desborda los moldes de lo determinado, dejando lugar a lo instituyente. Esta distinción también se puede encontrar en otros trabajos, como por ejemplo el de Maximiliano López (LÓPEZ, 2008), que cuando analiza la "Historia de la Locura en la Época Clásica" de Foucault, asocia a la facultad de la razón al ordenamiento, al poner límites a lo dado, a ciertas representaciones que serían producidas por otra facultad.

${ }^{4} \mathrm{La}$ " $x$ " que se encuentran en el texto tanto en los sujetos gramaticales como en los adjetivos que los acompañan, no son errores ortográficos, sino que responden a una posición político-epistémica, que no reconoce al género masculino como inclusivo del resto de los géneros, y que propone con su no determinación dejar abierta la posibilidad de definición genérica según las preferencias de cada cual. Es decir, que el uso de la "x" también se prefiere a otros tipos de escrituras inclusivas como ser "las/los", para despegar de las representaciones binaristas. A su vez, para facilitar su 
cambios en el sistema educativo? Consideramos que aunque la imaginación se presente como una capacidad ilimitada, tiene demarcaciones, fronteras, en las que deberíamos adentrarnos para indagar y quizás así llegar a comprender el “a pesar de" en la pregunta que abre este artículo.

\section{tres campos de la imaginación}

En un primer lugar, consideramos relevante dentro de la imaginación educativa en general, es decir, aquella que se pone en juego al momento de pensar la educación, delimitar diferentes campos de la misma, para indagar en su relación. Encontramos tres diferentes campos que denominaremos: imaginación pedagógica, imaginación política e imaginación didáctica.

Llamamos imaginación política a la facultad de imaginar nuevas formas de organizar lo social, de producir nuevas representaciones respecto de las posibilidades de la vida en común. Tiene que ver con la creación de alternativas a lo dado en la "polis" entendida como modo de organización de la vida colectiva. Si la pensamos desde el punto de vista de la educación, se manifiesta en la elaboración de políticas educativas, dentro de (y a veces innovando o modificando) los marcos curriculares y legislativos que regulan nuestras prácticas escolares. Muchas veces, por falta de articulación con la dimensión pedagógica de la imaginación, estos cambios a nivel macro-sistema terminan siendo transformaciones aparentes que no anclan en las subjetividades de lxs actores ni en la realidad educativa concreta. Nos referimos a políticas diseñadas en el marco de discursos innovadores, pero que no arraigan del todo en las prácticas cotidianas en las aulas de las instituciones. Con esto queremos indicar, que, en el último tiempo, se realizaron a nivel político por medio de disposiciones legales, ciertas reformas en la educación pública primaria de nuestro país, pero que sin embargo, las mismas no se concretizan en las instituciones a las cuales están dirigidas dichas legislaciones, no se llevan efectivamente a las aulas o a la esta posición. 
organización escolar, quedando en un ámbito formal de transformación. Consideramos que esto es en parte por no ser acompañadas de una reflexión pedagógica profunda, o por una movilización de la imaginación pedagógica que dé lugar a transformaciones reales y potentes, es decir, que no se da acompañando a la legislación una reflexión en las instituciones junto con todxs lxs actores educativos, ni antes de impulsarlas ni después, lo que podría llevar a que la transformación sea más real que formal ${ }^{5}$.

Por imaginación didáctica entendemos la facultad de ser creativxs a la hora de inventar "actividades y recursos", que se relaciona con el ámbito del cómo enseñar, con el espacio micro del aula. Este tipo de imaginación puede derivar en la mera aplicación de técnicas, procedimientos y recursos vacíos cuando carece de concepciones pedagógicas que le sirvan de marco. Incluso estas prácticas pueden entrar en tensión con imaginarios pedagógicos reaccionarios que desactivan su potencial transformador. Por ejemplo, cuando por innovar se propone una

\footnotetext{
${ }^{5}$ Entre otros ejemplos se pueden mencionar la legislación en torno a la obligatoriedad de la ESI en las escuelas o aulas. La ESI es el Programa Nacional de Educación Sexual Integral (ESI) creado por la Ley Nacional $\mathrm{N}^{\circ} 26.150$ del año 2006, que establece la responsabilidad del Estado en hacer cumplir el derecho de los niñxs y adolescentes a recibir Educación Sexual Integral en todos los establecimientos educativos públicos de gestión estatal y privada, desde los niveles de educación inicial hasta la formación docente. Y si bien consideramos es una reforma en muchos sentidos. Este Programa tiene un carácter universal, porque debe incluir a todxs lxs niñxs y jóvenes. Además se abordará desde una perspectiva integral, es decir, que debe abarcar todos los temas referidos a la sexualidad. Y a su vez, respecto de la temática de la diversidad de géneros y sexual, también se registrar un intento de inclusión y de abordaje crítico respecto de estereotipos de sujetxs, roles, familias, deseos, etc. Asimismo, da un lugar principal a las temáticas referidas al cuerpo. Entonces en este sentido se podría tomar como un gran avance para la educación y la sociedad en general incluir estas temáticas en la escuela. Sin embargo, se puede ver como en muchos casos concretos genera prácticas dogmáticas, encubridoras, o incluso heteronormativas. A partir de los contenidos propuestos por el Programa se puede determinar que es un discurso altamente normativo y regulador. Prescribe qué es la sexualidad, qué temas incluye y cuáles son los contenidos "normales" y "correctos" según la edad de lxs sujetxs. Entonces, todo lo que no se nombre dentro de estos contenidos y definiciones queda por fuera del ámbito de la sexualidad aceptada y correcta. Asimismo, respecto de la diversidad sexual y de género, anuncia y oculta determinadas cuestiones. Por un lado, presenta un alto nivel de binarismo en la enunciación de lxs sujetxs, es decir que se habla sólo de géneros masculinos y femeninos. Estos pueden intercambiar roles que antes estaban prescriptos para cada género y además incluye la posibilidad de no responder a sus estereotipos tradicionales, pero sin embargo, siguen siendo las dos únicas opciones de género en la que todxs pueden y deben reconocer. (Congreso de la Nación Argentina, 2006). En este sentido nos parece un buen ejemplo de estas políticas educativas que se presentan como inclusivas pero que terminan teniendo lógicas reproductivistas asociadas a la concepción de escuela moderna, que tiene el claro objetivo de formar y controlar las subjetividades correctas.
} 
disposición espacial de lxs estudiantes en ronda, pero hablan solamente lxs docentes.

Entonces, la imaginación pedagógica, que se representa las formas de pensar y vivir la educación (representaciones sobre la enseñanza, el aprendizaje, el rol de lxs docentes y estudiantes, la función social de la escuela, etc.) debería articularse con la imaginación política y la imaginación didáctica, para darles un sentido más profundo y posibilitar cambios estructurales, porque los tipos de imaginación que diferenciamos, son aspectos dinámicos de la imaginación, que se relacionan, articulan e influencian entre sí.

Creemos que es importante tener en cuenta la complejidad de este campo y evidenciar cuando ocurren cambios desarticulados que no devienen en transformaciones significativas ${ }^{6}$. Nos interesa penetrar y profundizar en la noción de imaginación pedagógica para así relacionarla con los otros ámbitos y aportar al desencorsetamiento de la educación. Propondremos otra demarcación importante respecto de la imaginación pedagógica, que lleva a pensar dos aspectos de la misma.

\section{la doble configuración de la imaginación pedagógica}

La manera en que nos representamos la escuela sigue operando en función a un orden de cosas que no ha cambiado, o que no ha cambiado lo suficiente. Se hace necesario entonces indagar la manera en que nuestra imaginación pedagógica está configurada en la actualidad.

\footnotetext{
${ }^{6}$ Esta fragmentación en las acciones que se realizan al interior de los campos mencionados, deriva en tensiones que se suscitan en el ámbito educativo. Por ejemplo, nos referimos a la simplificación de lxs docentes como meros ejecutores de políticas educativas, creadas por fuera de los espacios y realidades áulicas. Esto implica una mirada verticalista de las decisiones y cambios, que funcionan de forma descontextualizada y/o con pretensiones universalistas. Del mismo modo, podríamos mencionar que las prácticas innovadoras realizadas por lxs docentes en las aulas, no llevan a una reflexión general de transformación educativa ni repercuten en políticas concretas. En este caso, lxs docentes no se representan como sujetos capaces de transformar la educación más allá de las aulas. Consideramos importante aclarar que esto no depende de un puro voluntarismo docente, sino que se ve determinado por las actuales condiciones materiales: ausencia de espacios y tiempo de reflexión colectiva con pares e intercambios con otrxs actorxs del ámbito de la educación, precarización del trabajo docente, diversidad de contextos socio económicos de las realidades en que se insertan las prácticas y una formación docente que no alcanza a desarticular estas problemáticas.
} 
Entendemos que más allá de algunas valiosas transformaciones en los sistemas educativos actuales, nuestra forma de pensar y vivir la educación aún se encuentra fagocitada, de alguna manera, por las representaciones, valoraciones y criterios modernos de lo escolar. Esto afecta incluso a las posturas que se presentan como alternativas, ya que se definen en oposición a dicho modelo moderno. Nuestra imaginación parece sucumbir ante un modelo del que sorprenden sus simultáneas longevidad y vigencia. Aún algunos intentos de desarrollo de nuevas prácticas y pedagogías innovadoras como la introducción a gran escala de las nuevas tecnologías al interior del aula (TIC: Tecnología de la Información y Comunicación), la valorización de los conocimientos previos de lxs alumnxs como disparadores de indagaciones, la incorporación de la auto-evaluación de lxs estudiantes, entre otras, corren el riesgo de ser reabsorbidas por un sistema cuya capacidad de adaptación y mutación redundan en este paradójico carácter antiguo-actual. Parece ser que la imaginación y puesta en práctica de determinados cambios a pequeña escala en el día a día de la educación terminan siendo cooptados por una gran estructura escolar que no sufre modificaciones. Podríamos pensar aquí, siguiendo los ejemplos mencionados anteriormente, en la utilización de una pizarra digital del mismo modo y con el mismo sentido con el que se utilizaba previamente el pizarrón, en la búsqueda de conocimientos previos que luego serán dejados de lado, o en la utilización de la auto-evaluación como una evaluación más en relación a lo que lxs adultxs esperan de lxs niñxs.

En este sentido, si el sistema escolar hegemónico se apropia de la imaginación, no sólo de sus límites sino también de sus medios de producción, los regula e institucionaliza, ésta deja de ser lo que se esperaba de ella y pasa a ser parte del status quo. ¿Cómo recuperar una imaginación que nos permita ir más allá del orden escolar conocido?

Toda formación histórica tiene una manera de imaginar pedagógicamente, así como de imaginar didácticamente e imaginar políticamente, para remitir 
nuevamente a la expresión foucaultiana ${ }^{7}$ (FOUCAULT, 2012, p. 91). En la actualidad, aún seguimos atados a la imaginación pedagógica moderna ${ }^{8}$. Podemos, no obstante, identificar ciertas prácticas y/o discursos que han permitido salir de ese plano de representaciones, pero creemos que todavía hace falta producir nuevas formas de concebir lo escolar.

Este análisis nos lleva a plantear dos connotaciones diferentes de la noción de "imaginación pedagógica". Por un lado, una que podríamos llamar "situada", definida como la facultad que tiene toda época de imaginar pedagógicamente, es decir, de producir representaciones respecto a la educación. Esta facultad de constituir un imaginario es, en este primer sentido, propia de cada época y configura las maneras de percibir lo real de lxs sujetxs que viven en una formación histórica determinada. Es así que toda formación histórica tendría cierta imaginación pedagógica como campo o plano.

Por otro lado, existe otra connotación que tiene una implicación más propositiva, ligada al ámbito de lo deseable, que permite romper con ese

\footnotetext{
${ }^{7}$ A este respecto, puede resultar pertinente la siguiente definición y análisis: "[...] Las representaciones sociales son aquellas imágenes, visiones, percepciones, que funcionan como un mecanismo de interpretación colectiva sobre la realidad social y que dependen de los valores, creencias y formas de percibir e interpretar dicha realidad social. [...] Estas imágenes sociales son las que guían los discursos, las acciones, las formas de relacionarse, las normas sociales y legislativas, las políticas de infancia, las intervenciones. En definitiva, cualquier tipo de acción va a estar determinada por las representaciones sociales previas que sobre un tema o colectivo se tengan. Sin embargo, la propia naturaleza socialmente construida de las representaciones nos permite modificar su significado; por ello las representaciones sociales son repensables y susceptibles de ser negociadas [...]" (ANAVITARTE; CANTOS VICENT; MARTÍNEZ MUÑOZ, 2003, p. 22).

8 Con este concepto nos referimos al imaginario formado en: "el siglo XIX, que recoge e institucionaliza los planteos de Comenio (COMENIUS, 1998 - 8tva edición) (PALACIOS GONZÁLEZ, 1979, p. 7-13) respecto a la enseñanza sistemática y universal de los niñxs, que fue escenario de la institución de los sistemas educativos modernos, formados por escuelas organizadas en torno de una estrategia disciplinaria general: 1xs docentes y directivos ejercen sobre el cuerpo infantil una vigilancia constante, a fines de prevenir la producción de faltas, provocando en los niñxs la sensación constante de estar siendo vigiladxs. A esto Foucault (FOUCAULT, 2006, p. 146) le llamó "diagrama panóptico": donde el espacio se organiza según el "principio de localización elemental o de división en zonas", es decir, "A cada individuo su lugar; y en cada emplazamiento un individuo", a fines de evitar las agrupaciones confusas y de poder localizar a cada individuo, saber cuándo está y cuándo falta. A su vez, la arquitectura dispone una organización panóptica del espacio la cual, tal como su nombre lo indica, a través de un dispositivo económico (que habilita que un individuo controle a muchos) y de efectos permanentes, permite que el/la docente pueda tener a todo el curso bajo su mirada. (COLECTIVO FILOSOFARCONCHICXS, 2016, p. 22).
} 
¡qué aridez de imaginación pedagógica! pensar la escuela más allá de lo (im)posible

imaginario establecido, con el campo de lo ya dado y que llamaremos, tomando los aportes conceptuales de Castoriadis (CASTORIADIS, 2007) ${ }^{9}$ : imaginación pedagógica radical.

Entonces en este sentido más "radical", la imaginación pedagógica radical, sería imaginar y producir otras representaciones de lo real, para poder crear alternativas a lo que ya existe. Esto es, el gesto de imaginar nuevos modos de habitar la educación, aun cuando las nuevas representaciones sean difusas, abiertas, flexibles y no estén predeterminadas de antemano. La imaginación pedagógica radical es la capacidad de pensar más allá de las representaciones habituales de lo que pasa, o puede pasar, en la escuela, y conlleva e implica una movilización del deseo.

Pensamos que los modos de representarnos lo escolar, ligados a la Modernidad y la educación tradicional, sólo podrían cambiar si se dan en términos sociales ciertas prácticas que nosotros llamamos gestos de imaginación pedagógica radical. Estos gestos potentes y efectivos pueden ser pensados como condiciones para la producción de alternativas a lo posible en el campo de lo que entendemos por "educación".

\footnotetext{
${ }^{9}$ Nos referimos al concepto de "Imaginación radical" que Castoriadis (CASTORIADIS, 2007) acuña para intentar dar respuesta a cómo se dan los cambios sociales y como se instituyen las representaciones en una sociedad, partiendo de la teoría marxista y discutiendo con esta. Dicha corriente plantea que las condiciones materiales determinan la existencia, y Castoriadis se pregunta entonces: cómo surge lo nuevo si está todo condicionado, dónde está la libertad de lxs sujetxs, si todo depende de las bases económicas y las relaciones de poder que se dan en esa base. Propone entonces, que más allá de las representaciones instituidas que tienen que ver con la base económica, hay una dimensión de la subjetividad, que permite ir más allá de lo instituido y movilizar una dimensión instituyente, a partir de la cual se pueden realizar cambios en la historia. En las instituciones y en las subjetividades hay tanto una dimensión con determinada funcionalidad (instituida) como una dimensión imaginaria, que no está totalmente determinada por lo instituido, y que es lo que permite el surgimiento de lo nuevo a partir de lo ya instituido. Esta dimensión llamada "imaginario radical" es la capacidad de producción de lo nuevo más allá de lo dado, nuevas representaciones que son diferentes de todo lo que hay y diferentes a todo lo representado hasta el momento. La imaginación radical es definida como:

"Lo imaginario del que hablo no es imagen de. Es creación incesante y esencialmente indeterminada (histórico-social y psíquico) de figuras/formas/imágenes, a partir de las cuales solamente puede tratarse de «alguna cosa». Lo que llamamos «realidad» y «racionalidad» son obras de ello." (CASTORIADIS, 2007, p. 12)

"Capacidad de la psique de crear un flujo constante de representaciones, deseos y afectos. Es radical en tanto que es fuente de creación. Esta noción se diferencia de toda idea de la imaginación como señuelo, engaño, etcétera, para acentuar la poiesis, la creación". (ERREGUERENA ALBAITERO, 2002, p. 43)
} 
Consideramos que ha habido grandes gestos de imaginación pedagógica radical en la historia de la educación y de la filosofía ${ }^{10}$, que ilustran lo antes propuesto. Éstos inciden en el modo en que se distribuyen las visibilidades y las invisibilidades de lo que logramos o no concebir como posible. En esta clave, releemos los aportes de algunos autores como Mattew Lipman, Jacques Rancière y Walter Kohan ${ }^{11}$.

Matthew Lipman (LIPMAN, 1996) manifestó un gesto que movilizó el campo de la imaginación pedagógica cuando se atrevió a modificar la representación tradicional de la filosofía, que la planteaba alejada de la infancia, y de una representación tradicional de la infancia, que la postulaba como totalmente ajena a la filosofía, proponiendo el encuentro entre las mismas en el ámbito de la escuela. ${ }^{12}$ Este aporte que es reconocido por varios autores como Walter Kohan (KOHAN, 2004) y Gustavo Santiago (SANTIAGO, 2007, p. 78-81), es interpretado entonces como un gesto de imaginación pedagógica radical.

Jaques Rancière (RANCIÈRE, 2002) corrió nuestras representaciones colectivas de la imagen de lxs docentes sabios, que ocupan el lugar sagrado o poderoso del saber, postulando que "se puede enseñar lo que no se sabe" y que lxs maestrxs que realmente emancipan son aquellxs que se asumen como ignorantes frente a aquellxs a quienes enseñan, retomando, aunque en tensión con él, un viejo gesto socrático ${ }^{13}$.

${ }^{10}$ Los tres autores que se nombran y en relación específicamente a los postulados que mencionamos son interpretados por nosotrxs como gestos de imaginación pedagógica radical, es decir que los utilizamos como ejemplos ilustrativos de que entendemos por esto, a partir de una relectura propia a la luz de los conceptos propuestos, sin querer con esto abarcar toda su producción teórica y sentido de la misma.

${ }^{11}$ También se puede incluir como ejemplo de estos gestos los trabajos de Valeria Flores (FLORES, 2009), docente y militante feminista que investiga cuestiones de género y diversidad sexual, y que interroga nuestra imaginación pedagógica cuando en sus reflexiones sobre las modalidades que adopta la educación sexual en la escuela, cuestiona las maneras en que ese territorio de la imaginación se encuentra fagocitado por representaciones tradicionales y moralizantes de la sexualidad de adolescentes y niñxs.

${ }^{12}$ Además de su extensa producción en relación a la filosofía y la infancia, este gesto se evidencia, por ejemplo, en la creación de novelas filosóficas específicamente para chicxs de determinadas edades y su trabajo con ellas en la escuela con su programa Filosofía para Niños.

${ }^{13}$ Dice Rancière respecto del método socrático: “Es por eso que el método socrático, aparentemente tan cerca de la enseñanza universal, representa la forma más temible del atontamiento. El método socrático de la interrogación que pretende conducir al alumno a su propio saber es, en realidad, el de un domador de caballos: «Ordena los progresos, los avances y los contra avances. En cuanto a 
La filosofía de Walter Kohan (KOHAN e WAKSMAN, 2005, p. 69-80), profundizando el gesto lipmaniano ${ }^{14}$, abre nuevos interrogantes que invitan a repensar el encuentro de la filosofía con la infancia. Sus grandes preguntas significaron una ampliación de la imaginación pedagógica a la hora de pensar la filosofía en relación a lxs niñxs. Nos referimos a preguntas como: ¿Puede reducirse la enseñanza de la filosofía a la transmisión de habilidades lógicas y dialógicas? ¿Existe un método adecuado para la enseñanza de la filosofía que garantice un aprendizaje "exitoso"? ¿Discutimos filosóficamente sólo para ponernos de acuerdo? ¿Es la infancia asimilable a la niñez? ¿Se define esta cronológicamente?, entre otras.

La imaginación pedagógica radical implica un corrimiento de la mirada, de lo mirado y lo mirable. Este corrimiento es condición de una praxis transformadora y al mismo tiempo es movilizado por y se manifiesta en ella. En este sentido nos parece importante aclarar que no hay un solo movimiento transformador de la imaginación sino actos creadores, corrimientos de la mirada, que son siempre colectivos, aunque encarnen en individuxs que vehiculizan esos cambios con sus ideas y obras. La imaginación pedagógica radical no está anclada en un yo o en una

él, tiene el descanso y la dignidad del mando durante la doma del espíritu dirigido. De rodeo en rodeo, el espíritu llega a un fin que no había previsto en el momento de la salida. Se asombra de alcanzarlo, se vuelve, percibe su guía, el asombro se transforma en admiración y esta admiración le atonta. El alumno siente que, solo y abandonado a sí mismo, no hubiera hecho ese camino" (RANCIÈRE, 2002, p. 35)

14 Mathew Lipman es considerado el creador de la propuesta "filosofía para niños" como una respuesta a las falencias que él mismo encontraba en los alcances de la educación tradicional, principalmente en cuanto a la idea de pensamiento que subyacía a aquella. Él descubrió que lxs estudiantes llegaban a la universidad sin haber generado un pensamiento crítico y que a estos les costaba argumentar y dar cuenta de los supuestos y razones en que apoyaban sus conocimientos. A raíz de ello, genera un programa cuyo objetivo es desarrollar en lxs alumnxs habilidades lógicas y argumentativas que les permitan tener otro tipo de acercamiento a los conocimientos que se les presentan. A lo largo de su obra, desarrollará, frente a la preeminencia de esta dimensión crítica, también las dimensiones afectiva y creativa. No es que Lipman no haya considerado las últimas dimensiones, sino que puso el acento notablemente en la primera. En América Latina, Walter Kohan (KOHAN e WAKSMAN, 2005) y Gustavo Santiago (SANTIAGO, 2007), entre otrxs, retoman en su propuesta "Filosofía con niños" estas dimensiones, asimilando la dimensión crítica a: aquella que permite evaluar, juzgar, analizar, establecer conexiones, predecir, etc., situándola como una herramienta para hacer frente a la lógica del consumo reinante en la sociedad actual. Pero además, ponen el acento en la dimensión creativa, como "aquella que nos permite ir más allá de lo dado, construir algo diferente" y en la dimensión ética como aquella que se basa en considerar que "pensar mejor es pensar teniendo en cuenta a los demás". (KOHAN e WAKSMAN, 2005, p. 69-80) 
unidad subjetiva (individualidad), sino que pertenece al campo de lo impersonalcolectivo que a menudo aparece como irrupciones a través de pensamientos que invaden y trastocan el ámbito de lo pensable en educación.

Consideramos que estos gestos permiten movilizar, quebrar y subvertir el plano de la antes llamada imaginación pedagógica situada particular de cada contexto histórico. Y es nuestra intención en el presente trabajo, brindar aportes en consonancia con los movimientos propuestos en esta serie. Creemos que el pensar la educación en torno a las nociones de caos-acontecimiento ${ }^{15}$ y pedagogía prefigurativa 16, (desarrolladas en trabajos anteriores a éste (COLECTIVO

${ }^{15}$ Este concepto surge de un trabajo anterior en el cual la propuesta fue trabajar sobre (y repensar) ciertas representaciones que lxs docentxs tenemos respecto a lo que esperamos que suceda en las clases. Pensamos cómo los conceptos de "orden" y "caos" (en algunas de sus acepciones y usos) atraviesan el discurso educativo y las prácticas escolares, y moldean la mirada de lxs docentes sobre sus clases. Desde cierto punto de vista se considera que el "orden" es un atributo fundamental de lo que podríamos llamar una "buena clase" o un correcto funcionamiento del quehacer educativo. Un orden que tiene que ver con la disciplina, vigilancia y silencio, disciplina del cuerpo, del ruido, del movimiento, del azar. El caos entonces es entendido como lo opuesto al orden, lo des-ordenado, la ausencia de orden, aquello que en términos escolares se asocia a la indisciplina. En el fondo, ese caos que se opone al orden, deriva de ese mismo concepto de orden que lo define y lo determina como "falta de". Creemos que el concepto de "orden" refiere a las dimensiones instituidas y planificadas de lo escolar, pero deja afuera aspectos muy significativos como lo corporal y lo gestual, lo acontecimental o lo que emerge, otros tipos de temporalidad, etc. A partir de esta reflexión proponemos entonces, pensar la figura del caos-acontecimiento, no en oposición al orden y a la disciplina y definido en relación a ellos, sino como una noción independiente que remite a las condiciones de posibilidad del sentido y de la creación, y que opera como dimensión fundante de cualquier experiencia de ordenamiento posterior. Es el caosacontecimiento entendido como condición de posibilidad de la creación, como plano múltiple de producción de sentido, esto es, caos como materia prima, como lo que sucede genuinamente en una clase, antes de cualquier valoración, o imposición de una imagen mental predeterminada. Así, el caos se entiende como aquello que puede dar lugar a algo nuevo. Habitar el caos-acontecimiento es encontrar la potencia en lugar de aumentar los artilugios del orden. La potencia es hacer hablar al des-orden, preguntarse y habilitar la pregunta y la palabra, permitirse el desafío de nuevos "órdenes" multiplicados, originales, derivados de situaciones únicas. El caos-acontecimiento es una situación muy potente porque es genuina, porque manifiesta aquello único e irrepetible que caracteriza a cada aula, grupo, individux. El caos-acontecimiento puede ser el momento en que hablan todxs juntxs, episodios de agresividad como una pelea verbal entre chicxs, la falta de interés, las irrupciones o participaciones de lxs chicxs que van en otros sentidos al que se tenía pensado para la clase, etc. Son situaciones caóticas, a nuestro entender, porque salen de lo escolar/disciplinario, en ellas algo se sale de su lugar pre-asignado. Sin embargo, es necesario aclarar que no todo caos es fundante, como por ejemplo, el caos que prohíbe el vínculo con lxs otrxs o que impide en su totalidad la circulación de la palabra o la violencia, la anulación de lxs otrx, etc. (COLECTIVO FILOSOFARCONCHICXS, 2016, p. 21-28)

${ }^{16}$ Este concepto surge de trasladar el concepto de "política prefigurativa" de Hernan Ouviña (Politólogo y Doctor en Ciencias Sociales por la Universidad de Buenos Aires) a la educación, y a la vez, relacionarlo con el concepto de caos-acontecimiento. Ouviña (OUVIÑA, 2013, p. 77-104) se refiere con su concepto a las acciones políticas que se pueden llevar adelante en el presente y que 
FILOSOFARCONCHICXS, 2016, p. 21-38), implica un gesto de movilización de la imaginación pedagógica radical, que puede dar lugar a miradas y representaciones sobre lo escolar que abonen nuevas configuraciones sobre lo que sucede o puede suceder en la escuela y el campo educativo.

Dado que todos estos gestos disruptivos se dan en el marco de una determinada formación histórica, que como dijimos pone límites a la imaginación pedagógica, podemos profundizar esta reflexión preguntándonos ¿por qué la imaginación sigue anclada en el orden escolar conocido? ¿Por qué el imaginar insiste en sostenerse en lo dado y no se arriesga a pensar lo (im)posible?

Sostuvimos antes que la imaginación pedagógica radical produce diversos modos de concebir lo real que permiten movilizar el deseo para crear alternativas a lo que ya existe. Entonces, deberíamos indagar sobre los agenciamientos sociales de ese deseo que también encauzan y moldean la imaginación. La apuesta del siguiente apartado tiene que ver con una apelación a la figura de la imaginación pedagógica radical filiada ontológica y estratégicamente al deseo instituyente. La imaginación pedagógica radical es aquella que, movilizada por los derrames del deseo colectivo respecto del deseo socialmente agenciado, permite producir alternativas a los imaginarios dados en una época. Dicha imaginación, como un avanzar de un deseo inconsciente pero distinto al instituido (es decir, instituyente), es una instancia necesaria para dar lugar a algo nuevo.

\section{claves para la dilucidación de un deseo instituido y la movilización de un deseo instituyente en el campo pedagógico}

anticipan posibles cambios en el futuro. Al trasladar este concepto a la educación y relacionarlo con el de caos-acontecimiento, la noción de pedagogía prefigurativa permite postular que es posible iniciar una transformación en el presente, sin trazar un camino estático ni pensarlo teleológicamente. Pensar la práctica de la filosofía en la escuela en clave de pedagogía prefigurativa significa anticipar en el presente la escuela que deseamos, aun cuando el marco que las contiene tenga residuos de una escuela que aún tiene rasgos disciplinares y reproductivstas. Este concepto posibilita una transformación de las relaciones sociales educativas, tanto en su dimensión macro, es decir, acerca de la función social de la educación y micro, acerca de las subjetividades y sus relaciones, sin determinar el "hacia donde", cambiando la temporalidad, desde un sentido teleológico a un presente que construye sentido/s propio/s. (COLECTIVO FILOSOFARCONCHICXS, 2016, p. 29-38) 
Partimos en este apartado del concepto deleuzeano de deseo (DELEUZE e GUATTARI, 1995), y sostenemos que el deseo nunca es carencia -no es lo que falta sino justamente "producción de lo que hay" - y que es moldeado socialmente. Esto es, el deseo nunca está suelto, siempre está "agenciado", moldeado en alguna formación social e histórica determinada. No hay un deseo "libre", pero sí flujos de deseo que se pueden escapar de los códigos de una época, "derramando" o "chorreando" los agenciamientos a través de los cuales el deseo se encuentra organizado, y esto posibilita la dinámica social. Cuando algo pasa en la sociedad, hay una maquinaria deseante que lo sostiene. Entonces, si el imaginario moderno todavía no puede abrirse hacia un nuevo campo de la imaginación pedagógica, es porque aún está investido por nuestro deseo (o el deseo de muchxs). Por algún motivo seguimos deseando la escuela moderna, del mismo modo que para Deleuze y Guattari (DELEUZE e GUATTARI, 1995) seguimos deseando el capitalismo (aunque nuestras conciencias digan otra cosa) o como para Spinoza (DELEUZE, 2006, p. 18) o Rousseau (ROUSSEAU, 1995, p. 179-181) las personas se someten a servidumbres voluntarias, aunque nadie los obligue.

En el Anti-Edipo. Capitalismo y esquizofrenia, Deleuze y Guattari (DELEUZE e GUATTARI, 1995) hacen una distinción entre deseo y conciencia muy interesante para analizar algunas cuestiones sociales. Por ejemplo, afirman que una agrupación de izquierda puede querer conscientemente eliminar las relaciones jerárquicas, pero seguir al mismo tiempo reproduciendo ciertas prácticas verticalistas (porque el querer consciente no coincide con el deseo inconsciente). En ese sentido, los dispositivos de poder operan más con el deseo inconsciente que con las construcciones conscientes. Hasta que no se modifiquen unas será muy difícil que las otras sean significativamente transformadoras. Entonces, si bien desde la conciencia (o las catexis de interés, siguiendo la terminología propuesta por estos autores) podemos decir que no queremos más la escuela moderna, algo de nuestro profundo deseo (catexis del inconsciente) sigue manteniéndonos atados a esas estructuras. 
El deseo de una escuela en clave moderna puede pensarse hoy como un deseo instituido (que se habría gestado desde la Modernidad) que ahora se ve tensionado por un deseo instituyente, de otra escuela, que genera intentos de cambio y cuestionamientos parciales. En un sentido similar hemos planteado la existencia de dos tipos de imaginación pedagógica en tensión: una situada o enmarcada por una determinada formación histórica, y otra que tiene gestos que la trascienden, que es la que llamamos imaginación pedagógica radical.

¿Qué tipo de lógicas reproducimos y sostenemos al continuar deseando la escuela moderna? ¿A qué imágenes siguen atadas nuestras prácticas educativas y subjetividades docentes? ¿Cómo hacer para desactivar esos mecanismos de deseo $\mathrm{y}$ transformarlos en un deseo radical, transformador?

Creemos que el deseo instituyente (de otra educación y otra escuela) podría generar nuevas condiciones para que se pueda empezar a desear de otra manera. Pero despegar el deseo (instituido y parcialmente inconsciente) de esos viejos esquemas implica realmente un análisis de por qué los deseamos. Según Deleuze y Guattari (DELEUZE e GUATTARI, 1995), la dilucidación del deseo es importante para poder generar movimientos. Se vuelve necesario entonces analizar las prácticas concretas y sus efectos para ver en qué medida y cómo podemos generar acciones para transformarlas. Y si bien este no es el espacio para una empresa de dilucidación de deseo tan compleja, problemática y pretenciosa, nos contentaremos con señalar algunas claves que consideramos pertinentes tener en cuenta a la hora de pensar tanto la escuela actual, como las subjetividades que la habitan.

\section{caos-acontecimiento, pedagogía prefigurativa e imaginación pedagógica. aportes}

\section{y apuestas posibles}

En este apartado profundizaremos en ciertos gestos de imaginación pedagógica radical en los cuales vislumbramos algunas claves para pensar más allá de la escuela moderna: por un lado en relación a la figura del caos-acontecimiento (COLECTIVO FILOSOFARCONCHICXS, 2016, p. 21-28), que permite pararnos en las aulas más allá del orden-disciplina y las expectativas que este genera, y por 
otro lado, en articulación con la prefiguración pedagógica (COLECTIVO FILOSOFARCONCHICXS, 2016, p. 29-38), entendida como una posición no teleológica en relación a la educación. Por último, nos preguntaremos si es posible pensar nuevos órdenes escolares junto a niñxs y jóvenes, que construyan, piensen e imaginen la escuela que desean y deseamos habitar, aportando nuevos sentidos de la educación que posibiliten sociedades más igualitarias.

En primer lugar y retomando las consideraciones realizadas en "Figuras del Caos en el espacio escolar o iqué esperamos de una "buena" clase de filosofía en la escuela?" (COLECTIVO FILOSOFARCONCHICXS, 2016, p. 21-28) afirmamos que el concepto de orden escolar moderno sigue operando en lo que se constituye como esperable y deseable para lxs docentes; un orden entendido como silencio, inmovilidad, disciplina. De la misma manera opera el concepto opuesto, que señala aquello a evitar: el caos, la indisciplina. Nuestras expectativas como docentes -configuradas en torno a la noción y criterios de la figura del ordenmodelan las realidades que percibimos. El gesto evitativo, la inmunización con respecto a lo caótico, nos hace intentar imponer una realidad que está en la mente de lxs docentes, determinada de antemano, impidiéndonos ver la potencia de aquello que rompe con lo esperable. Creemos que este tipo de posicionamiento inmunizador y rígido de lxs docentes también señala una "zona de confort" de la que a veces resulta muy difícil e indeseable salir. El miedo a la incertidumbre y la dificultad de imaginar y dar lugar a otras posibilidades, parecen abonar un deseo de lo mismo, de lo cómodo y lo estable. Esto podría ser así por múltiples aspectos en donde los dispositivos de poder anclan: la comodidad que implica seguir ocupando el lugar del saber y del poder en el aula, la seguridad que genera ser el centro de la voz y el criterio de lo que puede pasar en las escuelas. Porque trabajar en el caos genera inseguridad, ansiedades, incluso sensación de que no se podrá cumplir con las expectativas planteadas por el sistema macro en el cual toda la experiencia escolar se inserta. No hay que olvidar que lxs docentes somos trabajadorxs en prácticas sistémicas que nos alienan y que demandan de nosotrxs ciertos resultados medibles. Por lo tanto, los dispositivos de poder operan sobre 
los deseos inconscientes instituidos y hacen que seamos nosotrxs lxs que de alguna manera reproducimos el sistema que por otro lado decimos rechazar.

Pero si en vez de sucumbir ante representaciones y expectativas modeladas a partir de una (y sólo una, única, fija e inmutable) noción de orden, dejamos de ver al caos como su opuesto, como aquello a evitar y reencauzar en él, estaremos predispuestos a encontrarnos con aquello que acontece, que emerge en un aula, que no es reasignable al orden instituido. Dejar de pensar en términos de pares opuestos, uno a mantener-reponer (el orden) y otro a evitar (el caos), nos permite habilitar un nuevo sentido del caos: el caos-acontecimiento. El caos entendido como aquello que da lugar y posibilita tanto la creación como la producción de sentido. El caos-acontecimiento tiene que ver con admitir una realidad, con sus puntos a favor y sus puntos en contra, para trabajar sobre ella evitando imponerle una imagen "modelo" hacia la cual debería tender. En el caos-acontecimiento se visibilizan otras dimensiones, antes "ocultas", fundamentales de lo que sucede en una clase: lo afectivo, lo corporal, lo grupal, lo lúdico, lo inesperado, lo irracional, aspectos cualitativos de gran potencial y riqueza para comprender el fenómeno educativo, para repensar nuestras prácticas e imaginar radicalmente. Lxs docentes pueden establecer una enorme diferencia de valoración con sus miradas y actitudes frente a lo que encuentran que está sucediendo en un aula. Evitar las valoraciones negativas inmediatas por el hecho de que no representan aquello que nos habíamos imaginado, es una clave de lectura transformadora. Leer una situación, analizarla y tomarla como materia prima para el trabajo sin modelos que la anticipen es el desafío. El orden/disciplina y el caos/indisciplina pueden suceder en cualquier clase, pero hay distintas maneras de plantarse ante el "caos", pensándolo más allá de la indisciplina, pensándolo en sí mismo, como elemento inconmensurable y no dicotomizable; como caos-acontecimiento.

En segundo lugar, en el trabajo "Prefigurar órdenes escolares posibles: el caos como clave para pensar una nueva escuela." (COLECTIVO FILOSOFARCONCHICXS, 2016, p. 29-38), la figura de caos-acontecimiento es retomada y asume una dimensión política que remite a la noción de "prefiguración pedagógica", como conjunto 
tanto de prácticas como de relaciones sociales y condiciones materiales de existencia que, en el momento presente, "anticipan" los gérmenes de nuevos órdenes escolares posibles, sin establecer (ni tener la intención de hacerlo) metas concretas o explícitas a las cuales llegar.

Esta noción está guiada por las ideas-eje de horizontalidad, solidaridad, conciencia crítica y acciones de organización, que habilitan una transformación de las relaciones sociales entre los miembros de la comunidad educativa (docentes y estudiantes, estudiantes entre sí, docentes entre sí, docentes y directivos). Estas ideas ejes, habilitan un marco intersubjetivo de relaciones para transformar las escuelas que habitamos y al mismo tiempo, nos desafía a pensar nuevos sentidos de la educación que posibiliten sociedades más igualitarias.

Desde sus orígenes la educación estuvo guiada por modelos de ser humanx y de sociedad que debía seguir, regidos por un modelo disciplinante y homogeneizante, que aún perdura en la actualidad. Nos alejamos de este modelo formativo y teleológico al proponer una perspectiva pedagógica en clave prefigurativa que abone la construcción colectiva de los nuevos órdenes escolares que deseamos. Como antes mencionamos, la noción de pedagogía prefigurativa nos permite anticipar en el presente la escuela que deseamos, a través de la modificación de nuestro pensar, nuestro sentir y nuestro hacer en el seno de prácticas concretas, aun cuando el marco que las contiene tenga residuos de una escuela moderna, disciplinante, homogeneizante, y al mismo tiempo, reproductora de la desigualdad. Si observamos desde una mirada en clave prefigurativa, percibimos ciertas prácticas que, aun cuando parecen hechos aislados, tienen repercusión en el ámbito educativo y que irrumpen o "desbordan" algunas de las características constitutivas del orden escolar moderno. Son entonces prácticas que habilitan a pensar relaciones no jerárquicas entre docentes y estudiantes, a abrir sentidos o a modificar la relación con el conocimiento y por lo tanto movilizan nuevos sentidos de la educación.

Recientemente y cada vez con mayor regularidad leemos que unx docente retoma y valora los saberes de un estudiante que considera "no sabe nada" (LA 
NACIÓN, 2016) frente a una instancia de evaluación o jóvenes varones de escuelas medias (O GLOBO DE BRASIL, 2014) deciden ir al colegio en pollera como medida de apoyo a una compañera trans a la que se le había inhabilitado el ingreso a la institución escolar, o que estudiantes realizan una toma del colegio como protesta por acoso del personal institucional a sus compañeras mujeres (PÁGINA12, 2016).

Por último, frente a esta apertura, pero aún en los límites del orden moderno que conocemos nos preguntamos: ¿cuál es el fundamento de la educación si corremos el aspecto teleológico de su función? ¿Si desarticulamos a la escuela como institución formativa de "futurxs ciudadanxs y/o trabajadorxs"? ¿Qué otros compromisos sociales puede asumir la escuela del presente? ¿Y si la enmarcamos en nuevos modos de relacionarnos con lxs niñxs y jóvenes? ¿Por qué educar para el futuro y no para el presente? ¿Por qué no pensar que son lxs estudiantes quienes tienen algo para decir y mostrar a lxs docentes y a sus pares? Dado que la escuela se ha pensado tradicionalmente como dadora de saberes, ¿en qué medida la misma se posiciona de manera receptiva frente a las experiencias vitales de lxs estudiantes? ¿Cómo pensar mecanismos que incorporen las miradas, sentidos y experiencias de niñxs y jóvenes, para pensar nuevos órdenes escolares? Si ampliáramos las percepciones y miradas, incluyendo estas voces, ¿podríamos concebir la escuela como un espacio en el cual pensar e imaginar juntxs cómo transformar las condiciones del sistema en el cual habitamos?

Nos referimos a la posibilidad de pensar mecanismos que habiliten el ejercicio efectivo de pensamientos y acciones de niñxs y jóvenes para intervenir en el ámbito educativo. No sólo en relación a la dinámica y contenidos al interior del aula sino también en relación a la organización institucional y a los sentidos de la educación en general, a través de la propuesta de políticas educativas que representen y visibilicen los deseos, necesidades e intereses de lxs estudiantes. Desde esta perspectiva, lxs niñxs y jóvenes son concebidos como sujetxs políticxs y deseantes en su presente, que contribuyen a la movilización de la imaginación pedagógica radical y a través de su participación aportan a la transformación de los 
sentidos de la educación en la construcción de nuevos órdenes posibles. No buscamos de esta forma volver adultxs a lxs niñxs, ni invertir el peso de las responsabilidades en la relación intrageneracional, sino poder habilitar la escucha y los mecanismos político-institucionales que pongan en juego lo que niñxs y jóvenes piensan y tienen para decir sobre sí mismxs, sobre el mundo que lxs rodea y sobre la educación.

(...) Serán los niños quienes construirán sus filosofías y sus modos de producirlas. No es mostrando que los niños pueden razonar como adultos que vamos a revocar el destierro de su voz, las voces de los sin voz, los in-fans. Por el contrario, en ese caso las habremos cooptado, lo que constituye otra forma de silenciarlas. Más bien, deberíamos prepararnos para escuchar voces diferentes como expresiones de filosofías diferentes, razones diferentes, teorías del conocimiento diferentes, éticas diferentes y políticas diferentes: aquella voz históricamente silenciada por el simple hecho de emanar de personas estigmatizadas en la categoría de niños, los no adultos (...). (KOHAN, 2000, p. 20).

En este sentido, no hay que desatender el hecho de que, a pesar de ciertas experiencias que expresan gestos de pedagogía prefigurativa, la escuela continúa manifestando en su interior relaciones sociales propias de las sociedades desiguales en las que nos encontramos. Las instituciones educativas se ven atravesadas por relaciones de poder inter e intrageneracionales que limitan la posibilidad de concebir en términos generales nuevos órdenes escolares. La funcionalidad de la escuela para el sistema social y la inserción de la escuela en la maquinaria capitalista, hacen de la productividad y la búsqueda de resultados medibles, entre tantos otros, aspectos fundamentales que devienen en criterios de lo escolar, y que a su vez evidencian el adultocentrismo ${ }^{17}$ imperante en las reflexiones y las prácticas educativas. El mismo reproduce en la escuela las jerarquías sociales y las relaciones de poder -y podríamos agregar, imposiciones de deseo- opresivas con las cuales el sistema capitalista suele organizarse.

De lo que se trata es de dilucidar esos mecanismos alienantes y la manera en que nuestros mismos deseos colectivos los sostienen y perpetúan. Incluso deberíamos interrogar nuestra propia relación con el poder en los modos que

\footnotetext{
17Tomamos el concepto de "adultocentrismo" como categoría que designa en nuestras sociedades occidentales, una relación asimétrica y tensional de poder entre generaciones y al interior de las mismas. Su objeto de estudio es el poder en las relaciones inter-intra generacional, no así una oposición adultx-niñx.
} 
tenemos de ejercerlo sobre lxs estudiantes. No para auto-culparnos como si todo dependiera de nuestras buenas (o malas) voluntades individuales, sino para señalar en qué medida nuestras miradas y nuestras prácticas son configuradas por dispositivos socio-históricos y por representaciones que se materializan en relaciones jerárquicas y adultocéntricas. Dichos aspectos, sumados a las limitaciones que cada formación histórica genera en la posibilidad de pensar cambios en la escuela, pueden ser desactivados si apelamos a la imaginación pedagógica radical como motor de transformaciones epocales de las prácticas.

En síntesis, creemos que pensar e imaginar la educación desde la connotación afirmativa que propone la imaginación pedagógica radical nos posibilita encontrar alternativas a lo que aparece como dado y nos invita a crear las condiciones para desbordar los límites del deseo. Asimismo, entendemos que los conceptos de pedagogía prefigurativa y caos-acontecimiento abren la posibilidad de construir una escuela que tenga valor y sentido por sí misma, y no sólo esté pensada en términos de producción social futura, aun cuando asumimos un compromiso con una escuela que aporte a una sociedad más igualitaria (y que se cuestione en qué medida reproduce desigualdades existentes, como las de clase y las de género). $\mathrm{Al}$ representar nuevas formas de mirar las prácticas, los sentidos y lxs sujetxs de la educación, las nociones de caos-acontecimiento y pedagogía prefigurativa expresan gestos de imaginación pedagógica radical hacia lo que aún no está dado, y lo que deseamos colectivamente. Si bien se mediatiza y manifiesta a través de ellos, la imaginación pedagógica radical no sólo es expresión, sino que es también condición de posibilidad que moviliza y potencia una pedagogía prefigurativa y un trabajo a partir del caos-acontecimiento como praxis transformadoras. Praxis que a su vez habilitan nuevos canales a través de los cuales la imaginación radical y el deseo podrán "chorrear" o desbordar lo ya dado, generando nuevas representaciones y configuraciones de lo real y lo posible, nuevas prefiguraciones $\mathrm{y}$ acontecimientos, para generar una dinámica transformadora. 
La imaginación pedagógica radical nos abre desde una mirada filosófica la posibilidad de irrumpir en los dispositivos de la escuela moderna. Se abre de este modo un nuevo campo en el cual trabajar. Una apuesta y a la vez un salto al vacío. Al vacío de lo incierto. De lo que se vislumbra, pero se pierde o se deshace al intentar ser razonado y argumentado. De lo que escapa a la lógica imperante y excede al campo de la razón. Entendemos y proponemos el trabajo con el acontecimiento, la prefiguración y la imaginación pedagógica radical como modos y claves para habitar ese vacío, volviéndolo potente y transformador.

\section{referencias}

ANAVITARTE, E. A.; CANTOS VICENT, R.; MARTÍNEZ MUÑOZ, M. De la participación al protagonismo infantil. Propuestas para la acción. Madrid: Plataforma de Organizaciones de Infancia, 2003.

BARGALLÓ, M. L. Educación sexual integral para la educación secundaria II: contenidos y propuestas para el. Buenos Aires: Ministerio de Educaión de la Nación, 2012.

CASTORIADIS, C. La institución imaginaria de la sociedad. Buenos Aires: Tusquets Editores, 2007.

COLECTIVO FILOSOFARCONCHICXS. Pedagogías del Caos. Pensar la escuela más allá de lo (im)posible. Buenos Aires: Seisdedos, 2016.

COMENIUS, J. A. Didáctica Magna o Tratado del arte universal de enseñar todo a todos. Mexico: Porrúa, 1998 - 8tva edición.

CONGRESO DE LA NACIÓN ARGENTINA. Ley N²6.150. "Programa Nacional de Educación Sexual Integral". Buenos Aires: 2006.

DELEUZE, G. Spinoza: Filosofía práctica. Buenos Aires: Tusquets, 2006.

DELEUZE, G.; GUATTARI, F. El Antiedipo. Capitalismo y esquizofrenia. Buenos Aires: Paidós, 1995.

ERREGUERENA ALBAITERO, M. J. Cornelius Castoriadis: sus conceptos. In: Comunicación, d. d. e. y Anuario de investigación II. México DF: UAM-X, 2002. p. 39-47.

Flores, V. (Mayo de 2011). Industrias del cuerpo. Ficciones feministas, fábulas epistemológicas y politicas del desacato. Obtenido de http://www.bibliotecafragmentada.org/wpcontent/uploads/2013/05/Flores-Valeria-Industrias-del-cuerpo.pdf Acesso em: 2016.

FOUCAULT, M. Vigilar y Castigar. Nacimiento de la prisión. Buenos Aires: Siglo Vientiuno (XXI), 2006.

FOUCAULT, M. El poder, una bestia magnifica. Sobre el poder, la prisión y la vida. Buenos Aires: Siglo veintiuno (XXI), 2012.

FRESSARD, O. El imaginario social o la potencia de inventar de los pueblos. Madrid: Revista Trasversales número 2, 2006. Disponivel em: http://www.trasversales.net/t02olfre.htm Acesso em: 2016.

KOHAN, W. La infancia escolarizada de los modernos. In: Infancia entre educación y filosofía. Barcelona: Laertes, 2004.

KOHAN, W. O. Filosofía e Infancia. La pregunta por si misma. In: KOHAN, W. O.; WAKSMAN, V. Filosofía para niños: discusiones y propuestas. Buenos Aires: Novedades Educativas, 2000. 
¡qué aridez de imaginación pedagógica! pensar la escuela más allá de lo (im)posible

KOHAN, W.; WAKSMAN, V. Filosofía con niños. Aportes para el trabajo en clase. Buenos Aires: Novedades Educativas, 2005.

LA NACIÓN. La docente que aprobó a una alumna que "no sabía nada". Buenos Aires: DIARIO LA NACIÓN, 12 Abril 2016. Disponivel em: http://www.lanacion.com.ar/1888837-la-docente-que-aprobo-a-una-alumna-que-nosabia-nada Acesso em: 2016.

LIPMAN, M. Pensamiento Complejo y Educación. Madrid: Ediciones de la Torre, 1996.

LÓPEZ, M. Filosofía con niños y jóvenes. La comunidad de indagación a partir de los conceptos de acontecimiento y experiencia trágica. Buenos Aires: Novedades Educativas, 2008.

MINISTERIO NACIONAL DE EDUCACIÓN ARGENTINA. Programa Nacional de Educaión Sexual Integral. Buenos Aires: 2006. Disponivel em: http://www.me.gov.ar/me_prog/esi.html?mnx=esi\&mny=_obj\&carpeta=esi Acesso em: 2016.

O GLOBO. Estudiantes van en falda al colegio en apoyo a compañera transexual. Rio de Janeiro: O GLOBO DE BRASIL, 15 Septiembre 2014. Disponivel em: http://www.eltiempo.com/mundo/latinoamerica/estudiantes-visten-con-falda-enapoyo-a-companeratransexual/14537975 Acesso em: 2016.

OUVIÑA, H. La política prefigurativa de los movimientos populares en América Latina. Hacia una nueva matriz de intelección para las ciencias sociales. In: Acta sociológica $\mathbf{n}^{\mathbf{o}}$ 62, Buenos Aires, p. 77-104, 2013.

PÁGINA12. El traslado de los preceptores. Buenos Aires: PÁGINA12, 19 Abril 2016. Disponivel em: http://www.pagina12.com.ar/diario/universidad/10-297278-2016-0419.html Acesso em: 2016.

PALACIOS GONZÁLEZ, J. La cuestión escolar. Críticas y alternativas. Barcelona: Editorial LAIA, 1979.

RANCIÈRE, J. El maestro ignorante. Cinco lecciones sobre la emancipación intelectual. Barcelona: Laertes, 2002.

ROUSSEAU, J.-J. R. Discurso sobre el origen de la desigualdad entre los hombres. Madrid: Técnos, 1995. 179-181 p.

SANTIAGO, G. Filosofía, niños, escuela. Trabajar por un encuentro intenso. Buenos Aires: Paidós, 2007.

recibido en: 24.10 .2016

aprobado en: 06.01.2017 